\title{
Virtual Dissection by Ultrasound: Probe Handling in the First Year of Medical Education
}

\section{(ㄷ)(i) (우) $\Theta$}

Authors

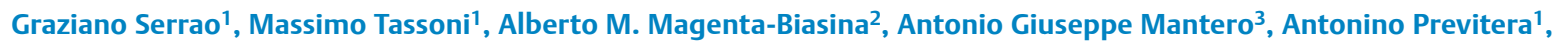
Michela Crisitna Turci² ${ }^{2}$ Elia Mario Biganzoli ${ }^{4}$, Emanuela A. M. Bertolini ${ }^{5}$

\section{Affiliations}

1 Università degli Studi di Milano, Department of Health Sciences, Milan, Italy

2 Azienda Ospedaliera San Paolo, Radiology, Milan, Italy

3 Azienda Ospedaliera San Paolo, Via A. di Rudinì, 8, 20142, Milan, Italy., Cardiology, Milan, Italy

4 Università degli Studi di Milano, Department of Clinical Sciences and Community Health, Milan, Italy

5 Azienda Ospedaliera San Paolo Via A. di Rudinì, 8, 20142, Milan, Italy., Epatology, Milan, Italy

Key words

ultrasound, interdisciplinary medical education, curriculum development, living anatomy, peer tutor

received 30.01 .2017

revised $\quad 05.09 .2017$

accepted $\quad 07.10 .2017$

Bibliography

DOI https://doi.org/10.1055/s-0043-121983

Ultrasound Int Open 2017; 3: E156-E162

(c) Georg Thieme Verlag KG Stuttgart · New York

ISSN 2199-7152

Correspondence

Prof. Graziano Serrao, MD, PhD

Università degli Studi di Milano

Department of Health Sciences

Via A. Di Rudinì

8, Milan, 20142

Italy

Tel.: + 39/02/50323186

graziano.serrao@unimi.it

\section{ABSTRACT}

Objectives The aim of the present study was to assess the educational plan of first-year students of medicine by analyzing their scores in ultrasound body scanning.

Methods Since 2009, the San Paolo Medical School (Milan, Italy) has vertically integrated the study of anatomy with ultrasound-assisted virtual body dissection. Three modules were supplied: musculoskeletal system, heart and abdomen pelvis. 653 first-year students were trained. The students alternated as mutual model and operator. A skillfulness score was assigned to each student. The scores were consequently listed. Nonparametric exact multiple contrast tests were employed to determine relative group effects.

Results Statistical analysis showed that: no gender-related differences were found $(0: 49 ; p=0.769)$; peer learners performed less well than peer tutors $(0.677 ; p=0)$; between modules, scores in the musculoskeletal system ( $\mathrm{pMS}=0.726$ ) tend to be higher $(p<0.001)$ than those obtained in the heart and abdomen pelvis $(\mathrm{pH}=0.398$; $\mathrm{pAP}=0.375 \mathrm{p}=0.270)$; significant differences were found compared to the beginning of the project's academic year.

Conclusion The students considered this didactic course an engaging and exciting approach. Acceptance of peer teaching was extraordinarily high. Autonomous exercitation allowed the students to improve self-criticism and enhance their own skills. The level of expertise obtained by peer tutors and by peer learners can be considered satisfactory. The main objective of training future physicians on personal stethoechoscope with the necessary competence seems to have been successfully started.

\section{Introduction}

\section{Supersonic anatomy}

Based on Swamy et al., in order to implement a practical approach in the preclinical phase of the medical curriculum [1-8], we carried out anatomy learning with ultrasound virtual dissection using a handy,

noninvasive $[9,10]$ and accurate expeditious tool. This procedure is safe, repeatable and devoid of degradation. In the footsteps of Metcalf and colleagues, we also implemented the study of anatomy in the living individual, defined as living anatomy, by inspection [11].

The focus of this educational project will be the ability to create the profile of a physician able to execute a first-level echography. 
A century ago, physicians had to master stethoscopes. At present, graduates should master miniaturized echoscopes. Moreover, ultrasound is at hand and guarantees accessibility to multiple body regions as well as immediacy and transferability. Unfortunately, most medical schools rely on clerkship and residency experiences solely to equip medical students with ultrasonography skills; this means the training is often limited to passive experiences with little or no participation in image collection [12]. We reasonably believe that a self-directed learning approach should improve student engagement and the autonomous use of diagnostic ultrasonography guidelines [9].

The present study shows an innovative didactic path that culminated in the exam test which assigned one credit in the core cur-

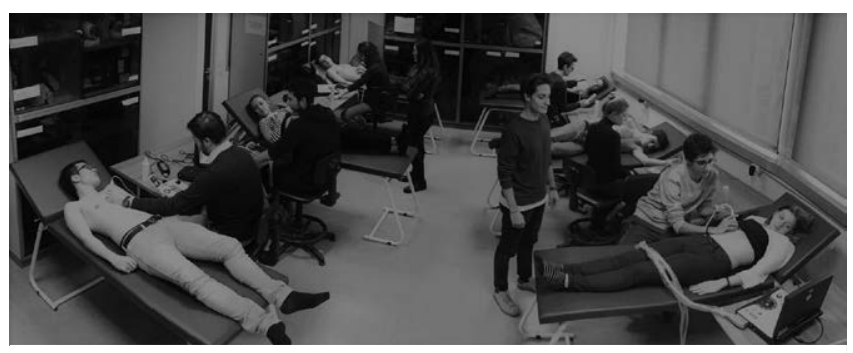

Fig. 1 A group of twelve peer learner, assisted by peer tutors

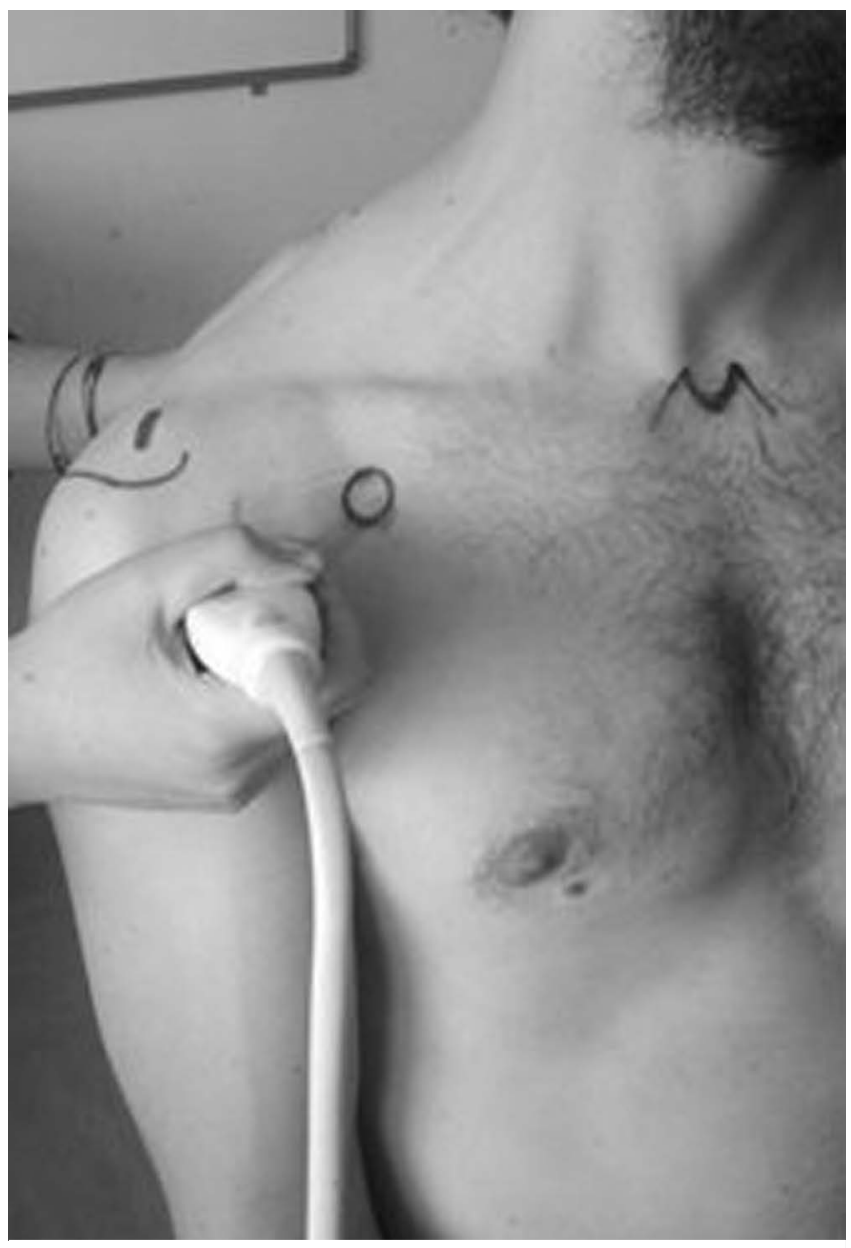

Fig. 2 Probe positioned on glenohumeral joint riculum of each student. In verifying the effectiveness of the learning plan, we conducted an analysis of the student's competence by using the scores obtained by each candidate during the profit examinations. So we compared the scores in the different modules and the scores of subsequent academic years.

\section{Participants and setting}

\section{Didactic plan}

Following the Hannover Medical School experience, a standardized curriculum developed by faculty ultrasound experts was presented to the student body [2,3]. The majority of students agreed to it. Since academic year 2009, the San Paolo Medical School (SPMS) Didactic Council has approved vertically integrated courses of anatomy, technical skills training guided by peer tutors [13-15] and ultrasound with an approved evaluation program. The SPMS then certified an "ultrasound core curriculum" training credit to students who proved they could adequately scan the required structures. In order to implement the project, the faculty supported the structure and ultrasound devices for the independent training of students. In the anatomy course, we adopted modules in which topography could favor the technology of the various probes from the surface (linear) to deeper tissues (convex). The training included the study of the musculoskeletal system, major arterial and venous vessels, visceral spaces of the neck (thyroid, carotid arteries, jugular veins), most of the viscera contained in the chest (heart), abdomen (liver, gallbladder, spleen, pancreas, kidney, aorta and branches, inferior vena cava and its tributaries, portal vein and its tributaries), and pelvis (bladder, uterus, ovary) [16]. All modules were supplied to small groups, each consisting of a maximum of twelve beginner students, assisted by clinical/peer tutors ( $\triangleright$ Fig. 1, 2). Each trained student participated alternately as a model and as an operator.

\section{Module 1: living anatomy}

Through the haptic interfaces, students located structures of interest (bones, epiphyses profiles, articular rhymes, muscles, tendons, ligaments, peripheral neurovascular bundles). For visual inspection and palpation, we adopted Tixa approaches [17]. In this module, students were tutored by the anatomists and the physical therapist. $50 \mathrm{~h}(\mathrm{~h})$ were devoted by each student to this section: $20 \mathrm{~h}$ were tutor-assisted, $30 \mathrm{~h}$ were self-training.

\section{Module 2: technical information about ultrasound scanning}

The class was introduced to the physical principles of echography and to the different probes used to perform it in two lectures held by their physics professor.

\section{Module 3: musculoskeletal system (MS) probing}

In this section, an ultrasound machine equipped with a linear multi-frequency probe (Logic QE, Medical Systems, Milwaukee, WI, USA) was used to study the MS, neurovascular bundles and the neck region $[15,18]$. During dedicated probe-in-the-hand sessions, each student practiced controlling the correspondence between palpatory detection and target structures (e. g.: rotator cuff tendons, 
ulnar nerve in the elbow, median nerve in the wrist, neurovascular bundles). Students were taught to recognize deeper structures of clinical interest, hardly traceable by palpation (e. g.: deep flexors/ extensors of forearm/leg; carpal tunnel). In the neck region, in order to evaluate right and left thyroid lobes, the probe was aligned with the thyroid cartilaginous prominence; two scans were conducted along the longitudinal and axial planes. $40 \mathrm{~h}$ were devoted to this section ( $20 \mathrm{~h}$ tutored; $20 \mathrm{~h}$ self-training).

\section{Module 4: thoracic, abdominal, and pelvic probing}

In this module, students applied topographical knowledge to identify the optimal windows to approach the region of interest. Students practiced on the chest, abdomen, and pelvis survey using both Logic QE and a pocket-sized ultrasound machine (VScan GE Medical Systems, Milwaukee, WI, USA). Students were taught to scan correct and complete images from the organ of interest. For instance, they had to perform the following ultrasound projections of the heart: parasternal long axis and parasternal short axis at the level of the semilunar cusps of the aortic valve, at the level of the mitral cusps and at the level of the papillary muscles, the apical four chambers and the two chambers [19, 20]. For liver scanning, we followed a sub-costal epigastric approach to study the left lobe and a transverse sub-costal or inter-costal approach to scan the right lobe. To explore and identify sectors, the liver was scanned with optimal windows to obtain the confluence of hepatic veins on screen. Liver segments were studied by observing right and left branches of the portal vein [21-23]. The spleen and kidneys were explored through long and short axes. Renal vascular segments were also studied. Positions, courses and main branches of major abdominal vessels were then explored.

This module required $80 \mathrm{~h}$ ( $40 \mathrm{~h}$ with peer tutors, and $40 \mathrm{~h}$ of self-training).

\section{Participants}

From 2009 to 2016, all 651 students attending the first year were trained with this approach. The student sample is reported in

\section{- Table 1.}

During each academic year, 16 first-year students volunteered in the training to become peer tutors. Expert sonographers (clinical tutors) directly trained peer tutors to obtain anatomically appropriate windows and correct complete scans for each region. The enabled peer tutors assisted the peer learners attending the same course.

\section{Evaluation parameters}

The acquired skills were verified by clinical specialists. In order to avoid assessment bias, the examiners evaluated the students they had not trained [24]. For each module, evaluation involved six main domains: i) skillfulness regarding regional topography/living anatomy; ii) window chosen for each scan plane; iii) description of the procedure; iv) communication skills; v) technical ability. Each scan procedure should be properly completed in no more than $5 \mathrm{~min}$. Hence for each single module, students had to be able to identify and recognize intrinsic landmarks to the target organ, necessary and useful to obtain repeatability, reliability and interchangeability in scanning. We assigned scores following these criteria: Fail $=0$ (below the expected level of competency), pass $=1$ (reflecting a
- Table 1 Student sample.

\begin{tabular}{|l|c|c|}
\hline Academic Year & Women & Men \\
\hline 2009 & 45 & 40 \\
\hline 2010 & 53 & 40 \\
\hline 2011 & 46 & 47 \\
\hline 2012 & 41 & 54 \\
\hline 2013 & 53 & 40 \\
\hline 2014 & 50 & 46 \\
\hline 2015 & 53 & 43 \\
\hline Total & 341 & 310 \\
\hline
\end{tabular}

borderline level of competency), high pass $=2$ (meeting the expected level of competency) and honors $=3$ (representing an above expected level) [25]. In any examination, assessment is always subjective. Therefore, we found standard validation to be superfluous.

\section{Data collection}

Within each academic year, the scores of first-year students, both peer tutors and peer learners, were listed. The percentage distributions of scores were then computed. Since the intended aim was to verify the requested familiarity with scanning via ultrasound structure, it seemed appropriate to use the same evaluation parameters for both peer tutors and peer learners.

\section{Statistical analyses}

In order to analyze data, we chose an $\mathbf{R}$ extension package called nparcomp [26], which can be used to compute nonparametric exact multiple contrast tests (MCTP) and simultaneous confidence intervals (SCI) for relative group effects. The MCTP function provides contrast matrices: "Tukey" for all-pairs comparisons, or change-point comparisons, takes the correlation between the test statistics into account. To analyze gender and peer effects, the approximate Brunner-Munzel test was chosen.

Our intent was to analyze groups, i. e., women vs. men and peer tutor vs. peer learners, for any academic year and module. Three modules were set: (1) musculoskeletal system, (2) heart and (3) abdomen pelvis. Current literature states that men and women differ in handling abilities and spatial orientation. For this reason, we wanted to verify any gender-related difference [27-30]. In the second step of processing, we analyzed the effect module on scores achieved by all students (peer tutor + peer learner). A priori we hypothesized that peer tutors would allow higher scores than peer learners because of motivation and for being expressly devoted to the course. The module and the academic year effects were studied by post hoc analysis.

\section{Results}

Generally, throughout the six years of observation, most tutees, either peer tutors or peer learners, scored levels 2 and 3. No peer tutors received a score of 0 . 


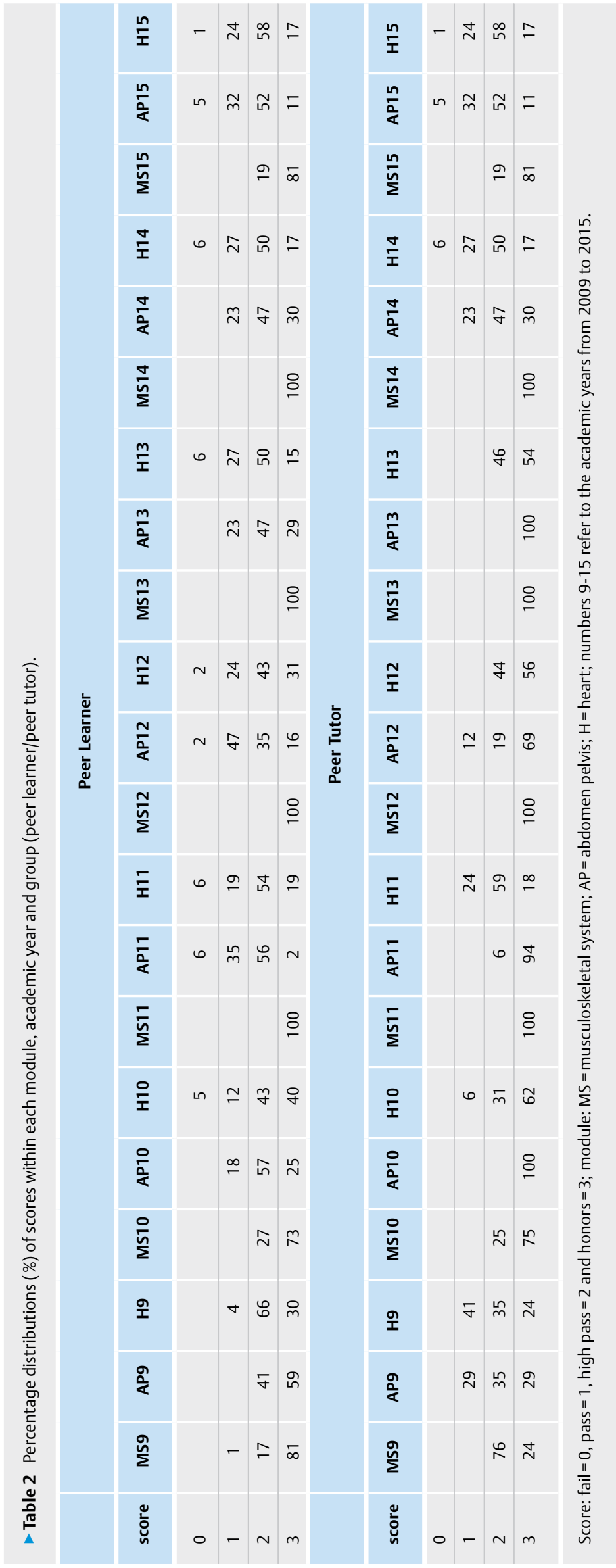


- Table 2, 3 show the analysis report concerning gender and peer, respectively. Over the years and in the different studied modules, our analysis did not find evidence of a statistically significant difference between the performances of women and men. The analysis showed that the women's group tended to be equal to the men's ( $0.49 ; p=0.769)$, and peer learners did not perform as well as peer tutors $(0.677 ; \mathrm{p}=0)$.

- Table 4 shows the analysis report concerning the three investigated modules. The skillfulness scores in the musculoskeletal system module $\left(p_{M S}=0.726\right)$ tended to be higher $(p<0.001)$ than those in the other two modules $\left(\mathrm{p}_{\mathrm{H}}=0.398 ; \mathrm{p}_{\mathrm{AP}}=0.375 \mathrm{p}=0.270\right)$.

- Table 5 resumes comparisons between peer tutors vs. peer learners within the academic year and module. Generally, peer tutors performed better than peer learners. Differences were significant in the heart module for all academic years and in academic years 2009 and 2014 in the musculoskeletal system module $(p<0.05)$. In academic year 2009, in the heart module, peer learners performed better than peer tutors, but the difference was not significant. Therefore, a prior hypothesis stating that peer tutors would perform better than peer learners had evidence for the abdomen pelvis modules in all academic years; for the heart module in academic years 2012, 2013, 2014 and 2015; finally, for the musculoskeletal system in academic years 2009, 2014 and 2015. Most of the differences between the performance of peer tutors and peer learners were significant $(p<0.05)$.

Generally, musculoskeletal structures appeared to be satisfactorily detected. In this regard, level 3 was scored by all first-year students in 2011, 2012, 2013 and 2014, and by the majority of students in the remaining academic years. Detection of the heart seemed to be the most difficult both for peer tutors and in peer learners. Although they had similar frequency distributions, the heart module scores were lower than those obtained in the abdomen pelvis module, particularly with respect to level 3 scores.

\section{Discussion}

From our data, the correspondence between anatomy palpation and ultrasound in the region of interest probably ensured optimal skills, while surveys of deep structures were more difficult. For diametrically opposed reasons, the heart and liver proved to be the core of complexity. Indeed, the heart is a small organ, rich in structures whose inclusion in basic scans is indispensable for a screening checkup. Slow and careful movements of the probe were required to obtain a correct and complete scan. Conversely, the liver is one of the largest organs in the human body, so good knowledge of topographical anatomy is required to identify the optimal windows to scan correct and complete profiles of the structures of interest.

According to the students, the use of ultrasound to learn about anatomy is a bridging tool. In their opinion, it improves the operational importance of anatomical knowledge.

Peer-assisted learning has been defined as a situation in which "people who are not professional teachers help each other to learn and learn themselves by teaching". Anatomy represents a typical field of medicine in which peer teaching systems are implemented into medical education [31]. Acceptance of peer teaching was ex-
- Table 3 Gender effects analysis.

Analysis Method = Brunner - Munzel - T - Approx. with 1928.785 DF

Sample Size F 987 M 956

\begin{tabular}{c|c|c|c|c|r|}
\hline & $\begin{array}{c}\text { Effect } \\
\text { Estimator }\end{array}$ & Lower & Upper & T & p-value \\
\hline (F,M) & 0.497 & 0.473 & 0.52 & -0.294 & 0.769 \\
\hline
\end{tabular}

- Table 4 Peer effects analysis.

Analysis Method = Brunner - Munzel - T - Approx with 646.312 DF

Sample Size: peer learner 1601, peer tutor 342

\begin{tabular}{|c|c|c|c|c|c|}
\hline $\begin{array}{c}1 \mathrm{p} \text { (peer } \\
\text { learner, }\end{array}$ & $\begin{array}{c}\text { Effect } \\
\text { Estimator }\end{array}$ & Lower & Upper & T & p-value \\
\hline peer tutor) & 0.677 & 0.654 & 0.701 & 14.618 & 0 \\
\hline
\end{tabular}

traordinarily high among tutees; well-trained peer tutors were widely appreciated and all tutees recognized their obligation to teach colleagues [32,33]. It is necessary to emphasize that peer tutors did not receive any contract or financial compensation from the faculty as student assistants. Through the implementation of the peer education model, the project of ultrasound anatomy established itself as a model which can be used by all students of the course [5, 14, 34, 35].

Taking account of the newness, the employment of peer tutors in training, the necessary arrangement in both processes of teaching and learning, which affected the attention of the learners, the level of expertise obtained by peer tutors and by peer learners can be considered satisfactory. To our knowledge, this professionalizing module delivered in the first year of the course of medicine has no precedent, although similar experiences are provided (rely on clerkship and residency) in clinical courses. It is obvious that the project beginning with the first year must be implemented by robust continuous undergraduate educational training with a vertical form of curriculum, in a preclinical and clinical strategy like that recommended by European Federation of Societies for Ultrasound in Medicine and Biology (EFSUMB). In agreement with Cantisani et al., we believe that it is essential to include the basics of US in the greater framework of general medical education [34].

\section{Limitations}

This study lacks the evaluation of possible differences in performance between untrained students vs. students trained in ultrasonic anatomy. From the point of view of vertical, shared and interdisciplinary teaching, we focused on the module following the guidance of clinicians in planning a virtual dissection experience that adequately tracks what traditionally competes at the core of anatomical teaching. However, we propose investigating this important aspect in a dedicated study. 
- Table 5 Peer tutor vs. peer learner effects analysis for academic year and module.

Analysis 1p (peer learner, peer tutor) $>1 / 2$

\begin{tabular}{|c|c|c|c|c|c|c|c|}
\hline Sample Size & Year & Module & Effect Estimator & Lower & Upper & T statistic & $\mathbf{p}$ \\
\hline \multirow{3}{*}{ Peer learner 68, peer tutor 17} & \multirow{3}{*}{9} & AP & 0.706 & 0.644 & 0.761 & 6.046 & 0 \\
\hline & & $\mathrm{H}$ & 0.371 & 0.246 & 0.515 & -1.762 & 0.078 \\
\hline & & MS & 0.596 & 0.548 & 0.642 & 3.882 & $\mathbf{0}$ \\
\hline \multirow{3}{*}{ Peer learner 77, peer tutor 16} & \multirow{3}{*}{10} & AP & 0.87 & 0.812 & 0.912 & 8.547 & 0 \\
\hline & & $\mathrm{H}$ & 0.632 & 0.493 & 0.752 & 1.868 & 0.062 \\
\hline & & MS & 0.518 & 0.398 & 0.635 & 0.29 & 0.772 \\
\hline \multirow{3}{*}{ Peer learner 77, peer tutor 17} & \multirow{3}{*}{11} & AP & 0.987 & 0.95 & 0.997 & 6.085 & 0 \\
\hline & & $\mathrm{H}$ & 0.511 & 0.381 & 0.639 & 0.159 & 0.874 \\
\hline & & MS & 0.5 & 0.462 & 0.538 & 0 & 1 \\
\hline \multirow{3}{*}{ Peer learner 79, peer tutor 16} & \multirow{3}{*}{12} & AP & 0.78 & 0.639 & 0.884 & 3.492 & 0 \\
\hline & & $\mathrm{H}$ & 0.678 & 0.557 & 0.78 & 2.826 & 0.005 \\
\hline & & MS & 0.5 & 0.461 & 0.539 & 0 & 1 \\
\hline \multirow{3}{*}{ Peer learner 79, peer tutor 16} & \multirow{3}{*}{13} & AP & 0.786 & 0.639 & 0.884 & 3.492 & 0 \\
\hline & & $\mathrm{H}$ & 0.678 & 0.557 & 0.78 & 2.826 & 0.005 \\
\hline & & MS & 0.5 & 0.461 & 0.539 & 0 & 1 \\
\hline \multirow{3}{*}{ Peer learner 78, peer tutor 16} & \multirow{3}{*}{14} & AP & 0.853 & 0.794 & 0.897 & 8.49 & 0 \\
\hline & & $\mathrm{H}$ & 0.771 & 0.657 & 0.855 & 4.227 & 0 \\
\hline & & MS & 0.526 & 0.501 & 0.551 & 2.037 & 0.042 \\
\hline Peer learner 80 , peer tutor 16 & \multirow{3}{*}{15} & AP & 0.913 & 0.861 & 0.946 & 8.758 & 0 \\
\hline Peer learner 80 , peer tutor 16 & & $\mathrm{H}$ & 0.938 & 0.89 & 0.965 & 8.529 & 0 \\
\hline Peer learner 70 , peer tutor 16 & & MS & 0.593 & 0.546 & 0.638 & 3.875 & 0 \\
\hline
\end{tabular}

In different courses, we ascertained different score levels. It may be that independent and strictly subjective proficiency behaviour occurred. The motivational aspects seemed to be critical regarding proficiency achievements. The lack of a clinical context probably undermined the attention in the scanning training.

\section{Implication for future improvements}

We hope that our didactic method will progressively become part of the core of medical practice, particularly with respect to the culture needed to use ultrasound effectively. The recommendation is to extend this competence to all medical students, in order to promote its adoption by nurses in blind maneuvers (such as blood withdrawals, intravenous therapies, catheterizations) as well as in rehabilitative ultrasound imaging (RUSI).

However, the main objective in training future physicians to handle ultrasonography with care and to prepare them for their professional life with the necessary expertise in using a personal stethoechoscope was successfully started $[35,36]$.

\section{Conflict of Interest}

The authors declare that they have no conflict of interest.

\section{References}

[1] Swamy M, Searle RF. Anatomy teaching with portable ultrasound to medical students. BMC Med Educ 2012; 22: 12-99

[2] Teichgräber UK, Meyer JM, Poulson Nautrup C, von Rautenfeld DB. Ultrasound anatomy: A practical teaching system in human gross anatomy. Med Educ 1996; 30: 296-298

[3] Rao S, van Holsbeeck L, Musial JL, Parker A, Bouffard JA, Bridge P, Jackson M, Dulchavsky SA. A pilot study of comprehensive ultrasound education at the Wayne State University School of Medicine: A pioneer year review. J Ultrasound Med 2008; 27: 745-749

[4] Brown B, Adhikari S, Marx J, Lander L, Todd GL. Introduction of ultrasound into gross anatomy curriculum: Perceptions of medical students. J Emerg Med 2012; 43: 1098-1102

[5] Serrao G, Costa G, Cecchini F, Ormas M, Turci MC. Ultrasonic anatomy: A professionalizing activity. Ital J Anat Embryol 2009; 114 (1 Suppl): 197

[6] Badea R. Medical education of students and residents a new paradigm? Med Ultrason 2012; 14: 175-176

[7] Mircea PA, Badea R, Fodor D, Buzoianu AD. Using ultrasonography as a teaching support tool in undergraduate medical education - time to reach a decision. Med Ultrason 2012; 14: 211-216

[8] Syperda VA, Trivedi PN, Melo LC, Freeman ML, Ledermann EJ, Smith TM, Alben JO. Ultrasonography in preclinical education: a pilot study. J Am Osteopath Assoc 2008; 108: 601-605 
[9] Fowlkes JB. Bioeffects Committee of the American Institute of Ultrasound in Medicine. American Institute of Ultrasound in Medicine consensus report on potential bioeffects of diagnostic ultrasound: executive summary. J Ultrasound Med 2008; 27: 503-515

[10] Miller DL. Safety assurance in obstetrical ultrasound. Semin Ultrasound CT MR 2008; 29: 156-164

[11] McLachlan JC, Patten D. Anatomy teaching: Ghosts of the past, present and future. Med Educ Mar 2006; 40: 243-253

[12] Syperda VA, Trivedi PN, Melo LC, Freeman ML, Ledermann EJ, Smith TM, Alben JO. Ultrasonography in preclinical education: a pilot study. J Am Osteopath Assoc 2008; 108: 601-605

[13] Weyrich P, Schrauth M, Kraus B, Habermehl D, Netzhammer N, Zipfel $S$, Jünger J, Riessen R, Nikendei C. Undergraduate technical skills training guided by student tutor - Analysis of tutors' attitude, tutees' acceptance and learning progress in an innovative teaching model. BMC Med Educ 2008; 8: 18-27

[14] Glynn LG, MacFarlane A, Kelly M, Cantillon P, Murphy AW. Helping each other to learn a process evaluation of peer assisted learning. BMC Med Educ 2006; 6: 18-27

[15] Knobe M, Münker R, Sellei RM, Holschen M, Mooij SC, Schmidt-Rohlfing B, Niethard FU, Pape HC. Peer teaching: a randomised controlled trial using student-teachers to teach musculoskeletal ultrasound. Med Educ 2010; 44: 148-155

[16] Butter J, Grant TH, Egan M, Kaye M, Wayne DB, Carrión-Carire V, McGaghie WC. Does ultrasound training boost Year 1 medical student competence and confidence when learning abdominal examination? Med Educ 2007; 41: 843-848

[17] Tixa S. Atlas of Surface Palpation. Anatomy of the neck, trunk, upper and lower limbs. Second EditionChurchill Livingstone Elsevier; 2008

[18] Tshibwabwa ET, Groves HM, Levine MA. Teaching musculoskeletal ultrasound in the undergraduate medical curriculum. Med Educ 2007; 41: 517-518

[19] Edwards WD, Tajik AJ, Seward JB. Standardized nomenclature and anatomic basis for regional tomographic analysis of the heart. Mayo Clin Proc 1981; 56: 479-497

[20] Waller BF, Taliercio CP, Slack JD, Orr CM, Howard J, Smith ML. Tomographic views of normal and abnormal hearts: The anatomic basis for various cardiac imaging techniques. Part I. Clin Cardiol 1990; 13: $804-812$

[21] Lafortune M, Madore F, Patriquin H, Breton G. Segmental anatomy of the liver: A sonographic approach to the Couinaud nomenclature. Radiology 1991; 181: 443-448

[22] Skandalakis JE, Skandalakis LJ, Skandalakis PN, Mirilas P. Hepatic surgical anatomy. Surg Clin North Am 2004; 84: 413-435

[23] Lafortune M, Denys A, Sauvanet A, Schmidt S. Anatomy of the liver: What you need to know. J Radiol 2007; 88: 1020-1035
[24] Heinzow HS, Friederichs H, Lenz P, Schmedt A, Becker JC, Hengst K, Marschall B, Domagk D. Teaching ultrasound in a curricular course according to certified EFSUMB standards during undergraduate medical education: A prospective study. BMC Med Educ 2013; 11: 13-84

[25] Colbert-Getz JM, Tackett S, Wright SM, Shochet RS. Does academic performance or personal growth share a stronger association with learning environment perception? Int J Med Educ. 2016; 7: 274-278

[26] Konietschke F, Placzek M, Schaarschmidt F, Hothorn LA. An R Software package for nonparametric multiple comparisons and simultaneous confidence intervals. J Stat Soft 2015; 64: 1-17

[27] Sykes Tottenham L, Saucier DM, Elias LJ, Gutwin C. Men are more accurate than women in aiming at targets in both near space and extrapersonal space. Percept Mot Skills 2005; 101: 3-12

[28] Moreno-Briseño P, Díaz R, Campos-Romo A, Fernandez-Ruiz J. Sex-related differences in motor learning and performance. Behav Brain Funct 2010; 6: 74

[29] Kolozsvari NO, Andalib A, Kaneva P, Cao J, Vassiliou MC, Fried GM, Feldman LS. Sex is not everything: the role of gender in early performance of a fundamental laparoscopic skill. Surg Endosc. 2011; 25: $1037-1042$

[30] Thorson CM, Kelly JP, Forse RA, Turaga KK. Can we continue to ignore gender differences in performance on simulation trainers? J Laparoendosc Adv Surg Tech A. 2011; 21: 329-333

[31] Krych AJ, March CN, Bryan RE, Peake B], Pawlina W, Carmichael SW. Reciprocal peer teaching: Students teaching students in the gross anatomy laboratory. Clin Anat 2005; 18: 296-301

[32] Blohm M, Krautter M, Lauter J, Huber J, Weyrich P, Herzog W, Jünger J, Nikendei C. Voluntary undergraduate technical skills training course to prepare students for clerkship assignment: tutees' and tutors' perspectives. BMC Med Educ 2014; 14: 71

[33] Wong I, Jayatilleke T, Kendall R, Atkinson P. Feasibility of a focused ultrasound training programme for medical undergraduate students. Clin Teach 2011; 8: 3-7

[34] Cantisani V, Dietrich CF, Badea R, Dudea S, Prosch H, Cerezo E, Nuernberg D, Serra AL, Sidhu PS, Radzina M, Piscaglia F, Bachmann Nielsen M, Ewertsen C, Săftoiu A, Calliada F, Gilja OH. Ultrasound Int Open 2016; 2: E2-E7

[35] Fodor D, Badea R, Poanta L, Dumitrascu DL, Buzoianu AD, Mircea PA. The use of ultrasonography in learning clinical examination - a pilot study involving third year medical students. Med Ultrason 2012; 14: 177-181

[36] Buckley S, Zamora J. Effects of participation in a cross year peer tutoring programme in clinical examination skills on volunteer tutors' skills and attitudes toward teacher and teaching. BMC Med Educ 2007; 7: $20-29$ 